\title{
Introduction
}

After two long days on the bus, I arrived in Sumbawanga in the beginning of February 2014, the rainy season well underway. The next day, I reported to the Mawingu Regional Hospital and stood up in front of the morning clinical meeting, with nearly one hundred hospital staff members staring back at me, to introduce myself and explain why I was there. I was proposing to research maternal death, a subject often accompanied by resonances of blame and failure on the part of individuals, institutions, and the state. I explained the goals of my research in a way that emphasized the need for the voices and perspectives of health care providers, those who were working hard to provide pregnant women with lifesaving care during emergencies, despite many challenges, and who are so often overlooked as whole people, or are taken for granted, in the reams of protocols and technical guidelines that policy makers and public health practitioners continue to turn out.

In less than three weeks after my arrival, we saw five maternal deaths on the maternity ward, one of whom was Paulina, the woman whose story opens this book. Over the course of the following fifteen months at the hospital, I began to unravel the complex intersections of history, geography, regional identity, state policies, political economics, biomedicine, and institutional and individual goals for providing and receiving care as these factors all influenced maternal health and death in the Rukwa region. Life on the maternity ward of a regional referral hospital is fast-paced and high pressure. Not only are these wards often understaffed and lacking material resources for lifesaving obstetric and neonatal care, but the nurses and doctors must respond to, and implement, a seemingly endless parade of new protocols and procedures, evidence based and Ministry of Health supported. All the while, women's and babies' lives rest in the balance, caught between the moment of what might be-an uncomplicated birth-and what sometimes occurs-a quick, often silent, turn of events that leaves one or both dying. 
A flurry of other activity constituted the background to Paulina's care on the day of her death. As she and Dr. Deo were in the operating theater fighting for her life, another woman came to the ward with a retained placenta. Even after a physician surgically removed the placenta, she continued to bleed heavily, still under the effects of the earlier general anesthesia and unable to call for help as blood pooled under her. Not twenty minutes later, another woman, Pascalia, started hemorrhaging after she gave birth. Nurse Rukia improvised a pair of elbowlength gynecology gloves (because the real ones were out of stock) and delved into Pascalia's uterus to manually remove the clots that were leading to the hemorrhaging. After she finished, Nurse Rukia had blood well up her arm, as well as where her makeshift elbow-length protection had given way; she was desperately calling for antiseptic to disinfect herself because of this blood contamination. Later that morning, relatives came to pick up a baby whose mother had died on the ward after giving birth the day before. In the afternoon, an eighteen-year-old woman arrived as a referral case from an outlying health center. She had started having seizures due to eclampsia from pregnancy-induced high blood pressure. Shortly thereafter, Nurse Lucy came back to the ward to deliver the news of Paulina's death in the operating theater.

As all of these emergencies unfolded, the nurses and doctors did their best to save lives and prevent other problems. In the aftermath of the death of any mother or baby, there was also a significant amount of paperwork. However, in the deluge of deaths that occurred during such a short three-week period, files went missing, and providers and administrators forgot details or were unable to follow up on a case as they might have wished. The resulting data that passed through the hospital, to the regional level and up to the Ministry of Health, were partial at best and hardly a reflection of the lives, the professional challenges, and the ethical and moral negotiations that went into each woman's care. Looking at the professional challenges and negotiations in the provision and reception of care that never made it into the reported data serves to pull back the curtain on the professionals who were supposed to prevent maternal deaths. Through these incidents, it is possible to see a workforce that is at once the cornerstone of the political and ideological humanitarian goal of reducing maternal mortality and also the invisible, taken-for-granted element in every facility-based birth-the nurse-midwives and doctors of the maternity service. As Nurse Aneth so aptly stated,

The maternity ward is the mirror of the hospital. ... I mean, you will find that in any hospital, a person will ask how is it, how is the language on the maternity ward? How is the care on the maternity ward? How is the drug supply on the maternity ward? How are the deaths on maternity? I mean, it's necessary. A person, if they reach any hospital, the person can be just passing, but they will say they are interested in knowing about the maternity ward. ... I think it is a sensitive department because it is the workshop, the factory for bringing people into the world after asking God for them. 
The negotiations the health care workers lived out on this ward serve, too, as a window not just onto the hospital but onto Tanzania's health care system more generally, as well as onto a global assemblage of institutions, bureaucracies, policies, and power that constitute the regimes of global health. Because of the complicated and unpredictable nature of obstetric emergencies, maternal death is a particularly sensitive indicator that quickly lays bare many health system gaps and weaknesses, making it a useful lens for examining the functioning of health systems but also individual biomedical institutions. ${ }^{1}$ Attending to the complexity of this work, especially the moral and ethical complexities that the nurses and doctors navigated each day, holds profound implications for our understanding of how facility-based maternity care is not the straightforward panacea for maternal death the global community imagines it to be.

As much as this book is about complexity-in work, in bodies, in institutions, in realities-it is also, first and foremost, about practices and ethics of care, both technical/clinical care and affective/emotional care. Particularly within health care settings, the word care appears in many different contexts. Before moving into a more in-depth discussion of care, we need to differentiate between technical care (which I also refer to as clinical care) and the less bounded affective forms of caring. Technical care is what we are referring to when we say health care services. This category includes procedures and tests, medication, surgeries, and monitoring of urine output, blood pressure, or fetal heart rates, among many other indicators. Health care workers have undergone training to be able to conduct these procedures or engage in these processes. Affective care, on the other hand, is a much fuzzier concept encompassing emotional engagement between patients and providers and responses to bodily but also mental and emotional needs; fundamentally, it is an intersubjective relationship.

In the obvious ways one might expect with a hospital ethnography, this book is about how health care providers, working in environments characterized by scarcity, care for their patients or fail to be able to do so. This book also tells how institutions may or may not be capable of caring for patients and for staff members because they are also sites, or conduits, of myriad forms of violenceranging from the physical to the structural. Too, these pages are about relatives and communities caring for pregnant women and how these groups understand maternal deaths or obstetric emergencies through their interactions with health care at a regional hospital but also closer to home, in village dispensaries. It is about how these people in communities are wounded by their interactions with their health care system through remembered and current incidents of corruption and exclusion. This book is also about how health care providers sought to care for each other through informal modes of accountability that protected them professionally (both within and outside their institution of employment). At the same time, sometimes these affective care acts for colleagues hid clinical 
mistakes, and the hiding challenged health care workers' personal, private morals and the professional ethics they believed to underpin good care. These ethical and moral challenges, the afterlives of informal accountability or other care acts between colleagues, escaped official documentation and visibility. But these care acts often helped hospital staff members reconcile their clinical and social actions with the burden of deaths that occurred on their watch. Ultimately, in far too many instances, bureaucratic, institutional, and social dynamics of the maternity ward, the hospital generally, and the overall health care system came together in ways that worked against a woman and contributed to the deterioration of her condition and her subsequent death, obstructing individual providers and state efforts to further reduce maternal mortality. The book also tracks maternal deaths and their roots outside hospitals, in communities, but also in historical precedents, in the world of funding and of material and human resources, and in global movements (or the lack thereof). However, "To understand these persistent patterns, one must look back to the period when the path was embarked upon, when the institutions were first constructed."' This is the task to which I now turn before coming back to care and this specific hospital.

\section{THE PROBLEM OF MATERNAL MORTALITY}

The problem of maternal mortality came of age alongside, and hand in hand with, a global expansion of data collection and disease surveillance. A confluence of contemporary currents of change and much older tides of interest launched the Safe Motherhood Initiative in Nairobi in 1987. Quietly, often in the background, colonial and postcolonial powers throughout Africa, and globally, had been debating the best ways to provide health care services for pregnant women when the time came for them to give birth. In British-controlled Tanganyika, present-day Tanzania, this meant years of memos back and forth arguing for or against institutional (hospital) and domiciliary (home) birth. ${ }^{3}$ The ultimate question always was and continues to be: Where is the best place for women to give birth, not only for their own health, but also to accomplish state goals? These state goals have taken various forms, shifting from educating or "modernizing" "Native" women in colonial-era Tanganyika so they might raise a certain, imagined type of ideal colonial subject, to achieving the Millennium Development and now Sustainable Development Goals in the present moment. ${ }^{4}$ With each new idea, with each policy oscillation between these poles of home and hospital, came new financial, bureaucratic, and medical implications for infrastructure, human resources, and experiences of caring for and being cared for. Maternal health, and reproduction more generally, can never be extricated from state making and perpetuation.

Throughout the 1970s and early 1980s, as data collection methods improved, and as second-wave feminism in the US and Europe influenced researchers and policy makers to look more closely at so-called women's issues, the global extent 
of the burden of maternal death began to come into view. Within maternal health, the current focus on data collection and utilization extends back to this period and

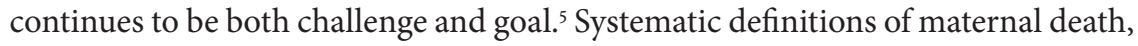
as well as greater understanding of the primary causes of these deaths, initially resulted from this time period. On the basis of this work, the World Health Organization (WHO) now defines maternal mortality as "the death of a woman while pregnant or within 42 days of termination of pregnancy, irrespective of the duration and site of the pregnancy, from any cause related to or aggravated by the pregnancy or its management but not from accidental or incidental causes," and it adds, "To facilitate the identification of maternal deaths in circumstances in which cause of death attribution is inadequate, a new category has been introduced: Pregnancy-related death is defined as the death of a woman while pregnant or within 42 days of termination of pregnancy, irrespective of the cause of death." ${ }^{6}$ Additionally, the WHO divides the causes of maternal mortality into direct and indirect causes. The direct causes are clinical conditions responsible for the majority of maternal deaths worldwide and include hemorrhage, complications from abortion (or attempted abortion), hypertensive diseases (such as eclampsia and preeclampsia), sepsis/infection, and obstructed labor. ${ }^{7}$ Pregnancy exacerbates some underlying health conditions, such as diabetes, HIV, malaria, obesity, or heart problems, leading to indirect maternal deaths. ${ }^{8}$

In 1985, two public health researchers, Allan Rosenfield and Deborah Maine, asked the world why maternal health was being neglected in widespread maternalchild health programs of the period; they reiterated findings from 1979 that more than half a million women were dying every year of pregnancy-related causes. ${ }^{9}$ This number, and the lack of attention for maternal health, shocked the global community and catalyzed a host of new organizations and initiatives, as well as a wave of policy priority setting. This historical moment gave birth to the Safe Motherhood Initiative and its Inter-Agency Group, a bricolage of organizations with sometimes-disparate interests, all loosely aligned around the goals of reducing these largely preventable deaths of women. ${ }^{10}$ Together, this group of organizations suggested a variety of interventions to reduce maternal deaths, all the while supporting more research into their causes, and into the more removed contributors to the deaths of pregnant women, such as low levels of education or a perceived lack of women's empowerment or low status in their communities. But globally, the complex, radically inclusive and systemic approaches needed to reduce maternal deaths still received less support than child survival programs. ${ }^{11}$

Concurrently, as the global Safe Motherhood Initiative was building momentum, the world was facing economic challenges, most severely felt in lower-income countries. The 1980 os were a time of drastic change for many nations in sub-Saharan Africa and globally as they tried to right their economies after the tumultuous 1970s had resulted in the collapse of global markets for the raw goods on which these economies depended. ${ }^{12}$ In Tanzania, home to Paulina and the setting of the events 
to follow, the country's first president, Julius Nyerere, was forced to step down under mounting pressure from within his own party to abandon his unique approach to African socialism, Ujamaa socialism. Tanzania's nine-month military conflict with Uganda resulted in the fall of the brutal dictator Idi Amin but also diverted considerable resources from other national activities. Faced with the realization that kujitegemea, or self-reliance, was no longer a viable strategy if he wanted to see his country's economy survive, but too committed to his ideological promises to the country some twenty years before to accept broad outside assistance, Nyerere stepped aside in 1985. ${ }^{13}$ The country's second president, Ali Hassan Mwinyi, immediately accepted loans from the International Monetary Fund (IMF) and the World Bank and, as a condition of these loans, implemented broad-sweeping reforms as part of the required Structural Adjustment Program (SAP). ${ }^{14}$

Just as many countries were cutting funds for social programs, including health care services-a move required by the SAPs as a condition for receiving aid-the global community was entreating low-income countries to commit to broad (and vague) campaigns to increase access to primary care and improve maternal health after the 1978 Alma Ata Conference called on governments to ensure citizens' access to health care and health through primary care. ${ }^{15}$ Structural adjustment in Tanzania also produced reduced wages for health care providers, exacerbating a general decline in living conditions and social service provision during the 1980 s and early 1990 s. $^{16}$ The longer-term effect was an increase in corruption, which proliferated rapidly and soon took firm root in the health sector in the late $198 \mathrm{os}^{17}$ Structural adjustment only worsened the financing problem for the Tanzanian health sector, which foreign aid had long kept afloat. ${ }^{18}$ In 1996, Tanzania decentralized the health care system, shifting the burden to the local level, where inequitable distribution of wealth and resources resulted in growing health rifts between regions. ${ }^{19}$ Around the same time, the country implemented user fees, which attempted to transfer some of the financial burden of services onto patients. ${ }^{20}$ However, user fees prevented many pregnant women from accessing needed services, and soon they, and select other groups, were exempted from fees thereafter. Where, then, were the funds to accomplish these primary health and Safe Motherhood goals meant to come from? And, crucially for the story that follows, who was imagined to be implementing these new forms of care and expanding services far and wide?

Tanzania's commitment to its socialist experiment meant that the primary care message of Alma Ata neatly aligned with the country's egalitarian socialist goals to ensure that Tanzanian citizens had access to basic health care, provided in Ujamaa villages via small dispensaries, which continue to form the basis of the country's health care system. ${ }^{21}$ By this time, Tanzania had been struggling for nearly two decades as an independent nation to provide health care services to the local population. A focus on primary care drew resources and investment away from larger facilities, such as hospitals, and resulted in increasing supply shortages and 
overcrowding. ${ }^{22}$ Despite these challenges, Tanzania was one of the first countries to sign on to the Safe Motherhood Initiative as a show of support for the initiative's direction and goals. This commitment built on the foundation the Ministry of Health had established in 1974 when it launched the first coordinated maternal health services in the country and formed a dedicated maternal health unit in the ministry. ${ }^{23}$ In 1988 the Ministry of Health produced Tanzania's inaugural comprehensive national health policy, the first objective of which was to reduce maternal and infant morbidity and mortality. ${ }^{24}$

Initially, faced with a global shortage of funds, infrastructure, and personnel, the Safe Motherhood Initiative advocated increasing access to antenatal care and training so-called traditional birth attendants (TBAs) as two ways to improve maternal health outcomes using already-present resources and in keeping with primary care objectives. Public health experts imagined antenatal care as a low-cost way to identify the women most at risk of developing an obstetric complication. Training TBAs - the name for people (mostly women) already acting as midwives in local communities, providing assistance to women in their homes-was another way to capitalize on existing resources. By training these women to use sanitary methods and recognize complications necessitating referral, public health professionals imagined that TBAs would be able to help reduce maternal deaths due to causes such as infection or obstructed labor. As it so happened, with more training, TBAs maintained, and even improved, their respected status in their communities, and more women utilized their close-to-home services. Particularly when biomedical services were poorly supported or low quality, women and their family members often chose the care of local healers and TBAs instead, reasoning that such care would cost less than the hospital and might be more effective, socially appropriate, and dignified. ${ }^{25}$ Conflicts between local beliefs and the practices of biomedicine were also an important factor affecting women's decisions regarding the use of biomedical health care services. ${ }^{26}$ Thus the original goal of TBAs referring more women to biomedical care was subverted, and women continued staying at home to give birth. Much like training TBAs, expanding antenatal care did not go as planned; as it turns out, it is an extraordinarily ineffective route for identifying women who will develop obstetric emergencies while giving birth or in the postpartum period. ${ }^{27}$ Like Paulina, many healthy women unexpectedly experience complications, and others with a lifetime of health problems can manage to give birth without issue.

If these two approaches-providing TBA care at home and referring women only when home-based care was not an option and increasing antenatal care to identify problems-were failing, what then was the solution to preventing the deaths of pregnant women ${ }^{28}$ As the global policy pendulum once again swung the opposite direction, the undeniable answer seemed to be that all women should give birth with the assistance of a skilled birth attendant in a biomedical health facility equipped with all necessary lifesaving supplies. Yet women's perspectives 
and ideas about where they would like to give birth were often left out of these policy-level debates, historically and in the present day. Giving birth at home has often been about giving birth in a familiar environment surrounded by people deemed socially appropriate. In contrast, biomedical health facilities are unfamiliar, hyperspecialized spaces constrained by the norms and rules of such institutions and facilitated by the knowledge, technology, and tools of their staff members. The unfamiliarity of this environment can, in many cases, amplify women's experiences of uncertainty during this life moment. Pregnancy and birth are already liminal states, marking important social life transitions, solidifying (when all goes well) a woman's place in her marital home, and fulfilling strong pronatalist cultural expectations. This period is also a fraught time, the success of which is threatened by both biomedical and supernatural forces that can steal away a woman, cornerstone of a family and community, and/or a baby, the promise of a new generation.

In the end, skilled attendance at birth came to be the linchpin of programming in the new era. ${ }^{29}$ The WHO defines a skilled attendant as "an accredited health professional ... who has been educated and trained to proficiency in the skills needed to manage normal (uncomplicated) pregnancies, childbirth, and the immediate postnatal period, and in the identification, management, and referral of complications in women and newborns," essentially what is now called basic emergency obstetric and neonatal care (BEmONC).$^{30}$ While the WHO makes this definition sound clear-cut, significant gray area exists. If a nurse went to school and was present in classrooms and during clinical rotations related to maternity care but cannot actually describe the signs of eclampsia when asked, is she skilled or unskilled? Technically, she would be grouped with skilled providers because she has a diploma, but functionally she is incompletely capable of providing emergency obstetric care. Alternatively, I have met TBAs, wakunga wa jadi in Swahili, who have no formal training but are able to cogently describe procedures for dealing with complications such as retained placenta in a way that many low-level, newly graduated enrolled nurses working in village dispensaries cannot. Who, then, is truly skilled, and do skills or papers (i.e., diplomas and certificates) matter more? This fundamental tension underpins much of what follows in this book. The biomedical institution itself cannot reduce maternal death; something more complex is at play in these places that challenges this clinical reductionism and complicates perceptions and beliefs about how to best prevent the deaths of pregnant women.

It was around this time, 2000, that the global community adopted the Millennium Development Goals (MDGs), a set of eight goals to reduce poverty and improve health. MDG 5 was to reduce maternal deaths by three-quarters from the 1990 level by the year 2015. ${ }^{31}$ In addition to structuring health sector priorities in many countries, the Millennium Development Goals helped to usher in an era in which indicators and metrics became a measure for the success, legitimacy, and validity of states and a marker of good governance from the local to the global 
level. For low- and low-middle-income countries such as Tanzania, evident progress toward meeting the MDGs became an important component of demonstrating deservingness for aid and investment, both from donor countries and from international organizations.

Only nine countries globally were able to achieve MDG 5 by the 2015 endpoint; many others failed to make significant progress. ${ }^{32}$ Across sub-Saharan Africa, home to fully two-thirds of these deaths, women still have a 1 in 45 lifetime chance of dying from pregnancy-related causes. ${ }^{33}$ In Tanzania, as the country attempted to reach these goals, they accepted support and interventions from numerous outside agencies, governmental and nongovernmental alike, resulting in the unstable "projectification"-reliance on shifting donors and policies-of the health sector, ${ }^{34}$ as opposed to comprehensive, synchronized efforts at reform and improvement across various areas of health services. For MDG 5 in the country, there is little evidence to suggest that the millions of dollars and scores of interventions poured into achieving this target have resulted in any sustained change. For example, as of 2016, Tanzania's maternal mortality ratio (MMR) was estimated at 556 per 100,000 live births, ${ }^{35}$ lower than the estimate for the period $2000-2005$ but higher than estimates from 2010 and 2012. Thus, as the Demographic and Health Survey states, "There is no evidence to conclude that the MMR has changed substantially over the last decade." ${ }^{6}$ Likewise, the Ministry of Health's website from 2018 says, "The maternal mortality ratio for births within institutions is not declining." ${ }^{37}$ Tanzania has demonstrated strong and consistent political commitment to addressing reproductive and maternal health problems. But unfocused efforts to improve care, lacking consistency and singularity of purpose, not to mention the needed financial and human resources, have long delayed further improvements for maternal health in Tanzania and mirror the troubled trajectory of the Safe Motherhood Initiative itself. ${ }^{38}$ After 2015, the Sustainable Development Goals (SDGs) replaced the MDGs, and a human rights framework now unifies seventeen comprehensive target areas, including reducing the global maternal mortality ratio to less than 70 deaths per 100,000 live births by $2030 .^{39}$

With the growth of research, guidelines, policies, and programs designed to help countries achieve lower maternal mortality has come rapid growth of bureaucracy. Anthropologist Matthew Kohrman uses the term biobureaucracy to describe the growth of institutions that have emerged with the "conceptual and practical orientation of advancing the health and well-being of people understood to have bodies which are either damaged, sickly, or otherwise different, based on local or translocal norms of existence"; ${ }^{40}$ biomedicine and its worldview are intrinsically linked to the expansion of bureaucratic institutions. ${ }^{41}$ In the case of maternal health, these "otherwise different" bodies are those for which pregnancy, labor, and delivery do not proceed problem-free. Though colonial efforts to increase birthrates and medicalize pregnancy "became enmeshed in the growth of bureaucratic state forms and la paperasserie of colonized life," the post-Safe Motherhood era 
has facilitated the birth of enormous global entities to reduce the most abnormal outcome (death) of one of life's most normal processes (reproduction). ${ }^{42}$

With biobureaucratic expansion has come an increase in modes of accounting for and measuring health. ${ }^{43}$ Despite this link with calls for greater (fiscal) accountability, various actors fabricate data for a variety of reasons and manipulate records of care, treatments, or diagnoses to correspond with expected outcomes. ${ }^{44}$ In many lower-income countries, the data on MMRs continue to be rough estimates generated through sophisticated statistical analysis. ${ }^{45}$ The nurses, doctors, and health administrators at Mawingu Regional Hospital grappled daily with increasing demands for data collection, preservation, and transmission. Their struggles to meet these demands illustrate the unintended effects of this global health fixation on numbers as it draws workers away from person-to-person caring.

Hospitals such as Mawingu are ground zero for the struggle to reduce deaths. Though more and more pregnant women arrive at this hospital with the expectation of receiving high-quality care, the number of deaths at the hospital has not declined, despite years of efforts to increase the number of highly trained providers, improve the availability of supplies, and implement all the Ministry of Health-approved and internationally sanctioned protocols, procedures, and plans. Despite clear evidence about the clinical causes of maternal death (hemorrhage, hypertensive conditions, infections) and the upstream contributors (low levels of education, poverty), why does maternal mortality remain such a seemingly intractable problem in Tanzania, and much of sub-Saharan Africa? What else can help to explain the slow progress toward this goal and all the failed interventions littering the road?

Within the field of medical anthropology, scholars have, since the 1970s, sought to explain why women continue to die during childbirth. Most commonly, these efforts have been based in understanding women's lifeworlds and rooted in explorations of women's perspectives and experiences with care seeking. Researchers have done the important work of aligning themselves with women and communities, often the more marginalized groups. Rarely, however, have these inquiries sought, or been able, to follow women into the very biomedical facilities now positioned by global policy as the route to saving women's lives. Yet the central debate about the appropriate place for women to give birth resounds in many of these earlier works. ${ }^{46}$ The fact of the matter is that if we examine only communities or only biomedical facilities we will not be able to adequately explain how and why women continue to die during pregnancy and while giving birth. Both anthropologists and public health researchers have thoroughly documented the community-level contributors. Now it is time to turn the anthropological lens on the biomedical facilities, where community meets specialized professionals.

Before reaching the specialized space of Mawingu Regional Referral Hospital, women most often pass through the other levels of the referral chain, starting with the local village dispensaries, which address basic, uncomplicated health needs. From there, a woman might seek more advanced care at a health center, usually 


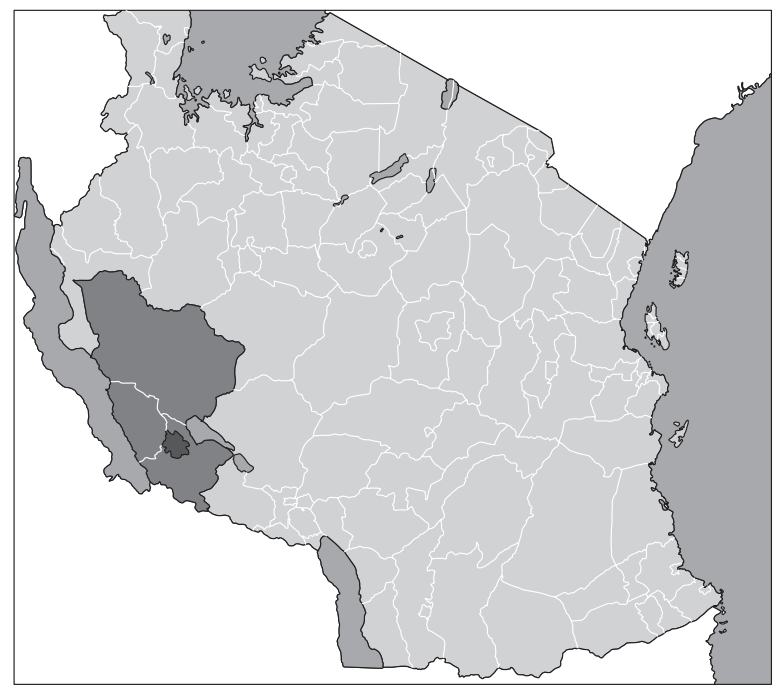

MAP 1. Map highlighting the Rukwa region, with Sumbawanga Urban District in the darkest color. (Available under GNU Free Documentation License, version 1.2 , no modifications made. https:// commons.wikimedia.org /wiki/File:Tanzania _Sumbawanga_Mjini _location_map.svg)

serving several villages and housing more equipment and additional, and more highly trained, personnel. Then, if health care workers were unable to address a woman's needs, they would send her to a district hospital if available (only two of these existed in the Rukwa region in which Mawingu is located). The regional referral hospital is the end of the regional referral chain. Should someone need more specialized care, regional hospital staff members might refer them to one of Tanzania's four zonal referral hospitals. As of 2013, people in Rukwa had to travel the furthest average distance to a health facility of any region in the country. ${ }^{47}$ After the tarmac road was finished in late 2014, the closest zonal referral hospital was four hours away by private car, but patients could undertake the journey only after the lengthy bureaucratic procedure necessary to arrange transport and secure official referral out of the region.

Rukwa is one of Tanzania's twenty-six mainland regions and includes four districts: Sumbawanga Urban, Sumbawanga Rural, Kalambo, and Nkasi (see maps 1 and 2). Despite my arrival at the start of the dry season in 2012, the landscape I encountered was still relatively green, and the tall, lithe eucalyptus trees that clustered in stands just beyond the side of the dirt road surprised me. The climate and feel of the region, high on the Ufipa Plateau some 5,900 feet $(1,804 \mathrm{~m})$ above sea level, was uniquely temperate, and I soon learned that dry-season temperatures often dropped into the forties or low fifties (Fahrenheit) at night. With a long rainy season and lower temperatures comes a long growing season on the plateau and, historically, protection from mosquito-borne diseases. However, the region also encompasses communities on the shores of both Lake Tanganyika to the west and the much smaller Lake Rukwa to the east. In these areas, the climate is much more 


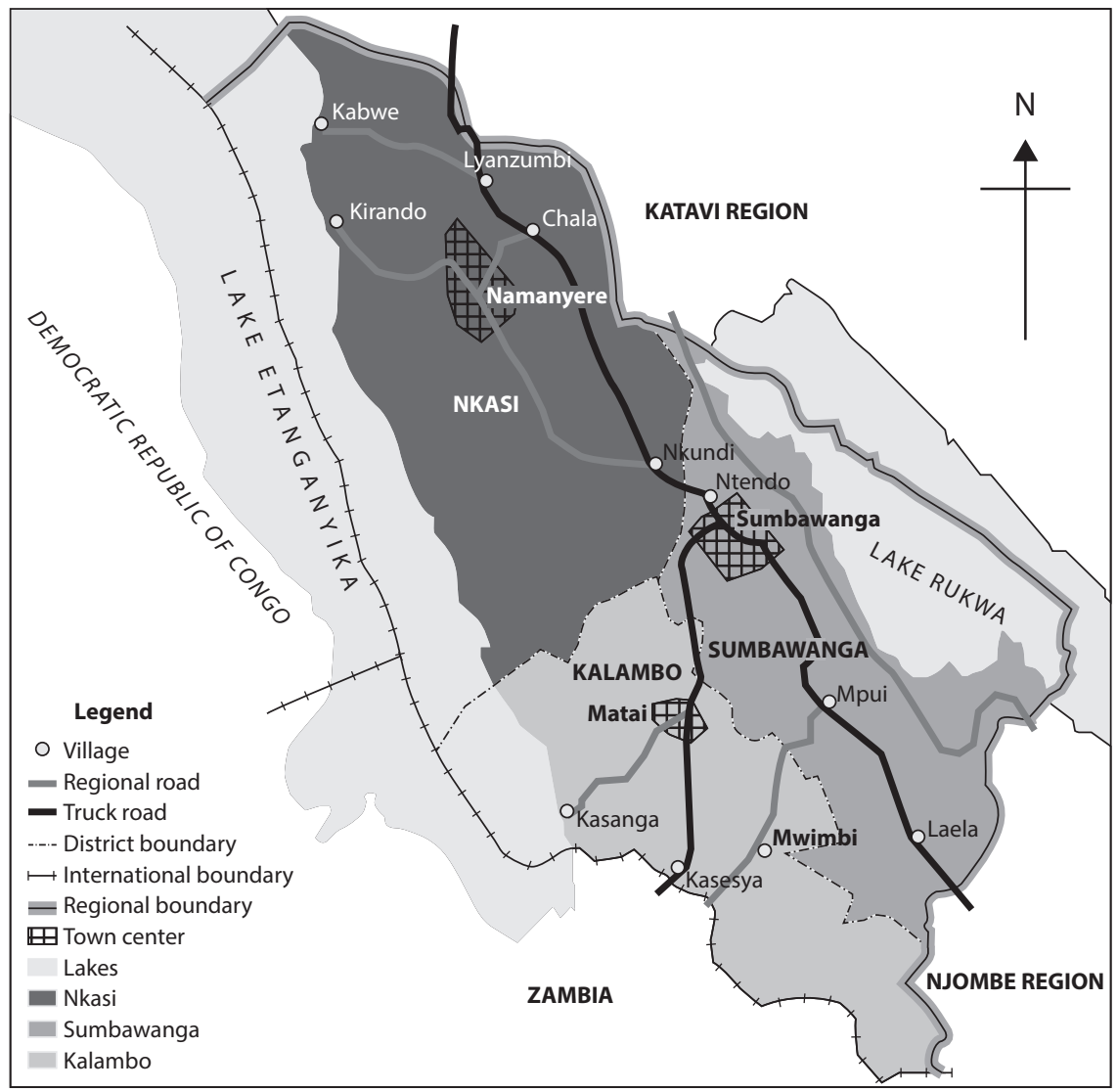

MAP 2. Map of the Rukwa region showing the three main districts, Sumbawanga Rural, Kalambo, and Nkasi. The Sumbawanga Urban District is the hatched area around the smaller word Sumbawanga, representing the town center.

tropical, fishing and rice cultivation are major sources of income, and mosquitoborne diseases are vastly more common.

Generally, the Wafipa people for whom the Rukwa region is home are subsistence farmers, growing maize, millet, rice, beans, and cassava; newer cash crops include sesame seed and sunflowers. ${ }^{4}$ The varied terrain provides numerous opportunities for agriculture and other economic activities but also presents substantial administrative and infrastructure challenges. Since the colonial period, there is a record of how cold temperatures and the long rainy season in this area have thwarted building projects. The tarmac road was completed only in November 2014, finally connecting the region's main town of Sumbawanga to neighboring regions. Some communities on the lake shores still lack access to cellular networks.

The region has historically been geographically and socially isolated, with a reputation as a home to powerful witches and traditional healers. ${ }^{49}$ I was repeatedly 
told that powerful witches in the region were known for being able to send lightning to kill someone. When I got in a taxi in Tanzania and told the driver where I was working, I invariably got a response along the lines of "Oh! But there are so many witches there!" The name Sumbawanga roughly translates to "to throw (away) witchcraft."

While people often told me the powerful witches in the region had long since fled to the bush out of fear of government persecution, many of the traditional healers, or waganga wa jadi, for which people also know Rukwa, have continued to run thriving businesses in the region. People from all over Tanzania, and even neighboring countries, seek the expertise of these healers for nonbiomedical ailments. According to early anthropological accounts, a Fipa healer sees his treatment "as an attempt to restore order to the two dynamic systems, one localized in the body, the other an invisible network of social relations, which together constitute the person for Fipa. . . . A large part of the average doctor's practice is concerned with meeting people's requests for treatment that will make them more socially effective." ${ }^{\circ}$ The Fipa idea that well-being encompasses one's social relations and interconnectedness with others is similar to concepts related to health and healing from across the sub-Saharan African world. The self and one's social network are intimately connected and together make the whole person in this worldview. In the Kifipa language, there is only one word for what English speakers would differentiate as medicine and magic, thereby demonstrating the conceptual relatedness of these categories in Fipa thought. ${ }^{51}$

Despite the power biomedicine now has globally, interconnectedness and relationships continue to shape the worldview of many sub-Saharan Africans; Afro-communitarian thought heavily influences social relations and interactions..$^{52}$ For the Fipa, these moral or ethical social commitments surface via beliefs that broken or misaligned social relations result in physical ailments, including pregnancy difficulties, especially obstructed labor. If people cannot resolve these pregnancy complications through social routes, women must seek biomedical assistance at one of the region's health facilities. There too, within the walls of biomedicine's primary institution, ethical social commitments and interconnectedness often direct interactions at the hospital.

Within Rukwa's Mawingu Regional Referral Hospital, a medical officer in charge and a nurse in charge oversaw each department. The patron and the assistant matron oversaw the nursing staff and reported to the hospital's overall medical officer in charge, who subsequently reported to the Hospital Advisory Board and the Hospital Management Team (HMT). The clinical (non-nursing) staff included medical officers (MOs), assistant medical officers (AMOs), and clinical officers, ${ }^{53}$ who, together with auxiliary staff, reported to the medical officer in charge. The auxiliary staff included laboratory staff members, medical attendants (semiskilled paramedical workers), pharmacy personnel, and other nonclinical support staff such as the hospital kitchen workers, security guards, and cleaners/ groundskeepers. 
The Obstetrics and Gynecology Department was more complex than any other department at the hospital. At Mawingu, the maternity ward is integrally connected to and dependent upon several of the other hospital departments, including Surgery, the laboratory, the Outpatient Department (OPD), Medical Records, and the gynecology ward.

The hospital administration coordinated activities with the regional medical officer (RMO), who oversaw all the health facilities and services throughout the region. The RMO, at the time of my fieldwork, was visibly involved in the daily functioning of the hospital and almost always attended the hospital's morning clinical meetings. He was an ally in creating and implementing the hospital's yearly goals and was responsible for ensuring that all facilities in the region implemented policies from the Ministry of Health. ${ }^{54}$

\section{HOW TO STUDY MATERNAL DEATH}

Research on the causes of maternal mortality in sub-Saharan Africa, the site of half of all such deaths globally, points to the combined and interrelated effects of poverty, lack of education, gaps in infrastructure, poor communication, and inadequate health care staff training. ${ }^{55}$ Undeniably, the biomedical health care system as a bureaucracy combines with these other complex dynamics to contribute to poor maternal health in Tanzania's Rukwa region. This case study of Mawingu Regional Referral Hospital reveals how the social world of biomedical facilities deeply and irrevocably shapes whether and which women survive obstetric complications, even when women are able to overcome structural barriers to these services. But beyond just providing us with insight into women's chances of survival, this setting of a regional hospital demonstrates the profound importance of understanding the experiences and strategies of health care workers. In trying to provide technical, clinical care services to women, health care providers, especially nurses, engage in subtle but significant ethical calculations and negotiations. To understand how these ethical negotiations affect pregnant women and their health, I have found theories of care and everyday ethics to be particularly useful tools with which to think. After discussing these theories, I finish this section with an explanation of my fieldwork methods.

\section{Ethics of Care and Care Practices}

Care and the nature of good care in Tanzanian maternal health care is the most fundamental thread throughout this book. Women like Paulina who arrived at Mawingu Regional Hospital at the ends of their pregnancies expected clinical care that would save their lives and protect their babies should an emergency arise. But more than that basic type of technical caring, many women expected or hoped for certain affective care relationships with their health care providers. Additionally, much of Tanzania's socialist past conditioned citizens to think of the state as a 
provider of social services, as a caring agent. Advocacy and awareness campaigns promoted this expectation, urging women and their partners to take advantage of biomedicine, provided by government facilities, for their pregnancy and delivery care. Beyond these elements, however, care came to play important roles across many other registers on the maternity ward at Mawingu. Providing affective care was one way nurses and doctors sought to be accountable to patients, and through their technical caring skills their own superiors, the government, and outside organizations judged providers' efficacy and professionalism.

To bring together all the forms of care, especially nontechnical, that the maternity ward and hospital setting generated, I draw on Erdmute Alber and Heike Drotbohm's definition, which states that care can be "understood as a social practice that connects not only kinsmen and friends, neighbors and communities, but also other collectivities such as states and nations. ... Care is a social and emotional practice that ... entails the capacity to make, shape, and be made by social bonds." ${ }^{36}$ This definition extends care beyond an intersubjective dyad of individuals to broader possibilities. In a hospital setting, the typical observer might expect to be most attuned to how nurses and patients or doctors and patients enter into these intersubjective caring relations and practices. Clearly, the expected relationships of care are present, but alongside these exist care relationships between doctors and nurses, nurses and nurses, the hospital and its workers, documents and nurses or doctors, supplies or technology and health care workers, ${ }^{57}$ as well as the state and citizen patients, and the state and its health care employees. All of these forms contribute to the generation of care as a multiplicity of practices in the biomedical setting..$^{58}$ Ideals about good and bad (nontechnical) care carry implicit messages about ethical care, or the ethics of care, and how health care providers negotiate possible and impossible care practices to enact ethical care in their settings.

The term "ethics" often evokes notions of a rationally derived, codified set of dos and don'ts of practice. However, Paul Brodwin's "everyday ethics" is more suited to the analysis at hand because it forces us to take very seriously how environment and context shape ethics and necessitate modifications and negotiation. ${ }^{59}$ These everyday ethics also consider actors' - in this case, generally doctors and nursesstructural position in their work environment, which helps to determine how they identify ethical problems, as well as their visions of good care.$^{60}$ Real-time, intersubjective care practices provide fertile grounds for examining these types of ethics, which become visible as nurses and doctors determine their responsibility to care for others and the ways in which they can in their work environment. These ethics become apparent when health care workers "must revisit their deeply held priorities concerning the good, the honorable, the obligatory" in the course of working with pregnant women. ${ }^{61}$

María Puig de la Bellacasa argues that "an ethics of care cannot be about a realm of normative moral obligations but rather about thick, impure, involvement in a world where the question of how to care needs to be posed. That is, it makes 
of ethics a hands-on, ongoing process of recreation of 'as well as possible' relations." ${ }^{2}$ Such relations become increasingly clear for the Tanzanian biomedical setting when examined through the lens of maternal mortality. This is a conversation not so much about the "oughts" of moral or ethical existence as about the "is": that is, how health care workers engage in their everyday care practices in a way they imagine to be ethical or not, moral or not, and how their health care system, poverty, and structural violence constrain the repertoire of ethical choices available to them in the context of providing maternal health services to women in the Rukwa region of Tanzania.

Examining (everyday) ethics of care on the maternity ward of Mawingu Regional Hospital reveals a nexus at which forms of ethical care that are local, specifically Tanzanian, rooted in African moral philosophies of interconnectedness, meet with forms of ethical care rooted in biomedicine and the Western philosophies that accompanied its spread in the colonial past and the contemporary era. ${ }^{63}$

In this local setting, the borders and boundaries of care versus abuse are not always clear-cut, and the recipient of care not always perceptible. Though women and nurses, as well as the doctors and administrators, were on the same side, striving for the same goal - the healthy birth of a baby and the continued health of the parturient mother-the institutional setting of the hospital, as shaped by state and global policies, not infrequently placed (especially) nurses and women in diametrically opposed positions, with the good of the one dependent upon the sacrifice of the other. Here the story of the Mawingu Regional Hospital's maternity ward should serve to demonstrate that the nurses and doctors worked in many ways unseen by women to buffer pregnant women and their babies from systemic deficiencies with no compensation and often at great personal cost, achieving some quiet forms of good care at the expense of other more visible goods.

These multiple versions of "good" that reflect not only particular, situated or subjective values but also different ways of ordering reality are an inherent attribute of care; care "implies a negotiation about how different goods might coexist in a given, specific, local practice." ${ }^{64}$ In the context of maternal health care, "different goods" enter the picture as each different actor seeks to give, receive, or demand care. The complexities and ambiguities of care practices arise throughout the book and form a central component of health care workers' struggles to create and enact ethical care in their daily work and encounters that demanded the intersubjective (re)creation of moral or ethical care practices. It is this ethics of care that I pursue here and begin to elucidate in the context of this specifically Tanzanian setting with specifically Tanzanian care practices, as well as the role this ethic of care plays in reducing, or sustaining, current rates of maternal death.

\section{Fieldwork}

Maternal mortality is an especially sensitive topic because of the deeply human desire to hold someone or something accountable for these never-anticipated 
deaths. As the nurses and doctors with whom I worked repeatedly told me, pregnant women are not supposed to die; pregnancy is not an illness, though they and lay people recognize the great danger that can threaten pregnant women during the pregnancy but most of all during their labor and in the immediate aftermath of giving birth. I arrived in Sumbawanga for the first time in 2012. Dr. Charles, Dr. Joseph, the medical officer in charge, and his wife, Dr. Akilah, had started working in Rukwa in late 2011, primarily through a program administered by the Benjamin Mkapa Foundation, named for its founder, the third president of Tanzania. The program recruited new medical doctors to work in underserved areas of the country through incentives for housing support and salary supplements. This cohort of doctors spoke differently of the region. Compared to those whom the government had assigned to work in Rukwa, they were filled with a certain zeal and commitment to improving maternal health care that had more ideological roots. They had willingly come to Rukwa as reformers. Likewise, the Rukwa regional medical officer told me the government had moved him to Rukwa in early 2012, just one month before my own first visit. His reputation as a successful reformer in another remote area had most likely made him particularly suitable, in the eyes of the government, to work in this new location. There was a sense of movement and change following on the heels of their arrivals, and the 2010 Demographic and Health Survey, which had clearly shown that the Rukwa region was behind the rest of the country on nearly all indicators related to maternal and reproductive health. Therefore, when I arrived and started discussing plans to investigate maternal health in the region, I met with an exceptionally receptive audience; they were eager for allies. Because many of the providers and administrators were new, they were less threatened by my proposal to investigate the roots of these deaths, knowing, as they did, that the roots significantly predated their own arrival and thus their responsibility. They all felt a certain mandate to reform and improve care and joined a stronghold of a few others long engaged in the crusade to help pregnant women.

At Mawingu Regional Hospital I participated in nearly all aspects of the life of the hospital. I worked at the hospital at least five days per week and started each morning attending the clinical meeting at 7:30 a.m. On the ward, I observed surgeries (primarily C-sections and the occasional fistula repair or evacuation postabortion/ miscarriage), assisted nurses with the intake and discharge of patients, took vital signs, and filled out paperwork related to birth records, labor progress, doctors' rounds, death certificates, and patient consent forms as dictated to me. I also tested urine for protein (a sign of eclampsia), took blood samples to the hospital lab, collected lab results, restocked supplies, provided laboring mothers with comfort measures, delivered babies, and resuscitated newborns, as well as mopped floors, took equipment to the autoclave, helped fetch supplies, and performed other basic tasks that arose as part of daily life on the maternity ward. To contextualize events in the hospital, I also visited more than twenty communities and worked in the Tanzania National Archives. 
I did not start my fieldwork with the intention of being involved in clinical tasks on the ward because I am not a clinician and am neither trained nor certified in any sort of nursing, midwifery, medicine, or paramedical field in the United States. However, despite my intentions, while I was at the hospital in 2013, one of the senior nurse-midwives who was also a nationally certified trainer of trainers in basic emergency obstetric and neonatal care (BEmONC), told me I should be more helpful on the ward and decided to train me in how to conduct uncomplicated deliveries. Simply scribbling away in my little black notebook had become untenable. Initially, I protested, telling her that I did not know how and that therefore I felt it would be unethical for me to perform these tasks. In her no-nonsense manner she quipped, "Well, I am going to teach you and then you will know! Besides, there will always be someone else here even if you are doing the delivery." With that, my education commenced. These interactions with Nurse Gire exemplify the complex negotiations that Gitte Wind describes as negotiated interactive observation in hospital ethnography; the ethnographer also becomes "an object for the Others' interpretation and social engagement.... At least some if not all of an ethnographer's informants will watchfully scrutinize all her actions, attitudes, comments and questions." ${ }^{35}$ Gire's scrutiny of my dedicated scribbling led her to determine that this type of work did not satisfy her and, in her view, was incompatible with the setting in which I could be taught to be a useful additional set of hands.

Ultimately, I engaged in "observant participation,"66 through which I learned, though initially unwillingly, several aspects of being a nurse-midwife and, under supervision and only when human resource shortages necessitated, worked in a version of that capacity. None of this experience made me a midwife, a specialized profession of which I am not a part. However, under the watchful and exacting eyes of Nurse Gire, I learned to properly, safely, and respectfully assist women during uncomplicated births. As she had said, there were always nurses on the ward, but after much supervised practice I did sometimes deliver babies on my own. This happened only when all of the nurses were occupied with other women. Always, the nurses and doctors knew what I was doing and came to assist as soon as they were available in order to ensure that women received appropriate, safe, and effective care. A deep respect for women's rights and dignity, as well as their bodily autonomy, underpinned all that I did.

In preparation for this fieldwork in 2014 and 2015, I pursued training in the United States as a doula, or birth support person, in the hopes of being useful on the ward in this capacity. Doulas provide comfort measures and pain management strategies for women in labor but, perhaps most importantly, serve as a witness to the woman's labor and birth, whether picture-perfect or prolonged and traumatic. This witnessing is often the most valuable tool a doula has to offer and is not terribly different from the similar gift an adept ethnographer can provide through interviews and presence. Because I was not a nurse, I was at liberty to spend more sustained amounts of time with individual women while they were in labor on the 
ward. I often would stay close to the beds of women who were young or expressed fear or concern amid their contractions. I would rub their backs, apply counterpressure, hold their hands, or simply sit nearby. The greatest offering I had was time; the nurses often made fun of me for spending hours with one woman, so indulgent did this seem in their setting of personnel scarcity. In one instance, I spent hours standing beside a woman as she silently and excruciatingly worked to deliver the body of her baby who had long since died in utero. All I had to give her was my presence, my witness to her silent, determined, and grim work toward a known and distressing outcome. Most of the time, these were the ways in which I participated in births.

I want to emphasize, too, that my whiteness and foreignness surely influenced how people read my presence, opening additional avenues for participation that would have been closed in other settings. Often the only other white people in these settings in Tanzania are foreign medical professionals, and, as such, it was easy for the hospital staff members to slot me into that preexisting category with which they were familiar. Therefore, it would be reasonable to think that people, especially those with whom I interacted less frequently, would not question my actions or level of participation. In fact, as often happened, they might question why I was not doing more if they assumed I was a doctor or nurse. I stopped far short of what the nurses would have liked me to do and often requested of me: I always refused to do vaginal exams, start IVs, or perform other invasive procedures.

While academics and others in the global North may consider my level of participation controversial, it was necessitated by the environment of the hospital and was supported, facilitated, and supervised by local experts and authorities. The providers on the ward drew me into a locally appropriate and necessitated form of relationality. Local norms and forms of acceptable sociality required this level of participation during moments when the choice was either me or a woman giving birth with no help, possibly resulting in danger to the baby or the woman herself. My involvement does raise ethical questions. To not engage in the ways in which I was invited to would have been a form of ethical violation when I was there and capable of doing so. What would a denial to help, to "get dirty" alongside the nurses, and instead an insistence on sitting only in my privileged, tidy world of orderly black notebooks, have meant for relationships with others in this setting? What would have been the ethical implications of withholding my ability to help in some of the situations unfolding in front of me on the ward, particularly when the hospital staff members were invoking my assistance? In this way, my presence and participation are irrevocably entwined with the broader discussions in this book about the everyday, hands-on, "thick, impure, involvement" in, and production of, the ethics of care in this setting. ${ }^{67}$

In engaging in these activities on the maternity ward, I deferred to and respected local authority and sovereignty. I was also taught by locally recognized experts. No, I would not be qualified to deliver babies in the United States because I lack 
paperwork and official qualifications or certificates. Instead, an African woman in Tanzania taught me, transferring her expert knowledge via apprenticeship, which, in the global system, does not count as much as that of institutionalized classroom training in a high-income country. So too, the nurses and doctors with whom I worked would be barred from immediately practicing nursing or medicine in the United States because of complex mechanisms of power and inequity, with roots in racism and colonialism, that continue to systematically devalue and discredit knowledge and expertise from places like Tanzania.

Over the course of a total of twenty months, I spent more than 1,600 hours on the Mawingu maternity ward. I did not even attempt to conduct any formal interviews with the hospital staff members and administrators until I had been at the hospital for over a year. During that time, and through the activities in which I participated, the nurses in particular came to trust that I knew the difficulties of their work environment and would not report or blame them or violate that trust. It was this combination of deep involvement and sustained presence that led to the rich interviews that resulted and the intimate portrait of the ward and hospital that follows here. Throughout the text, I use pseudonyms for the hospital and its health care providers, as well as their clients. I have made sure no health details would reveal the identity of a woman or her family or jeopardize the jobs of the health care workers. For those people whose official title would identify them, I received their explicit permission to use their quotes with their titles. Since the time of the fieldwork, many of the nurses, doctors, and administrators have changed positions or are no longer working at Mawingu Regional Hospital.

The prevailing message women receive from public health campaigns, their government, and health care providers tells them that the hospital (or other biomedical institution) can save them from any and all complications related to childbirth if only they know how to use that institution. Knowing how to use the biomedical system encompasses embodying institutionally appropriate patient compliance, deferring to health care workers, arriving early in labor, coming prepared with supplies such as gloves and umbilical cord clamps or oxytocin injections, and knowing how to navigate the institutional bureaucracy in order to arrive in the right place within the hospital at the right time. Any deviations or delays can result, so the discourse goes, in a complication or death that is not the fault of the hospital's personnel but merely the result of the woman's own inability to effectively tap into the power of biomedicine through early and appropriate access to care. In contrast, in the pages to follow, I argue the fundamental point that the very institutions that politicians, clinicians, public health and policy practitioners, and the public have imbued with the power to save lives and have invoked as a panacea to solve the maternal mortality problem are, instead, at the root of systemic failures to improve maternal health outcomes and care. The role these institutions are supposed to play is repeated and elevated in a sort of collective fantasy or imaginary about how to reduce maternal deaths, without adequate acknowledgment of 
how these institutions have failed to progress, not clinically, but socially or organizationally, in order to reduce these deaths. This imaginary of the all-encompassing power of biomedical institutions also does much to deny the global and local inequity and systemic scarcity that forces deviation, justification, and improvisation that does not meet international best-practice guidelines. Certain forms of care (technology-based biomedicine that originally accompanied colonial conquest) have achieved ascendancy through metrics, data collection, and the reduction of bodies to numbers and checkboxes. Other forms of care, more affective and relational, have been effectively quashed within the biomedical system because of institutional scarcity, often the result of biomedical and biobureaucratic expansion that sought to accomplish too much, too quickly.

The second goal of this book, the first full-length ethnographic examination of what transpires in a government maternity ward in a low-resource setting, is to present a thorough and nuanced portrait of how health care providers and administrators work to deliver maternal health care services and uphold the ethical ideals of their professions within a bureaucratically and structurally constrained system. What emerges is a complex, discomfiting picture of shifting forms of accountability, patched together and resewn under duress, both professional and personal, as nurses and doctors sought to provide health care and save women's lives, doing the best they could under conditions of scarcity. African biomedical health care providers and administrators have long been "functionally invisible" in scholarship. ${ }^{68}$ Understanding the complex inner processes of health care institutions and their staff members, and care as one form of an ethical "institution," has become even more important with the continued emphasis on biomedical birth to reduce maternal deaths. In every policy created and implemented, the health care workers are the ones meant to carry them out. However, they remain unnamed or unacknowledged in so many of these documents, even as policy makers and experts expect them to do ever more, often with the same, or fewer, resources. 